\title{
Sexo e anarquia: uma combinação explosiva
}

\section{Anarchism \& Sexuality: Ethics, Relationship and Power.}

HECKERT, Jamie;' CLEMINSON, Richard. ${ }^{2}$

Oxon: Routledge Taylor; New York: Francis Group, 2011.232 p.

Com lançamento simultâneo na Inglaterra, nos EUA e no Canadá, esta coletânea, que abarca temas como sexo, anarquismo, teoria queer, política e cultura, vai, certamente, impactar os leitores brasileiros discutindo conexões inexploradas nessa latitude. Trata-se de uma coletânea interdisciplinar importante para os Estudos Feministas, a Teoria de Gênero, a Sociologia da Sexualidade e os Estudos Gays e Lésbicos. A intenção dos autores era produzir um texto iconoclasta de leitura vibrante, com forma e conteúdo inusuais, conseguiram!

Além de as discussões serem originais e atuais, oferece uma entrevista inédita na qual Judith Butler atualiza ideias sobre cultura e políica, sexo e gênero. O livro contempla as tradições do pensamento anarquista em fricção direta com - lebenswelt da sexualidade contemporânea. Questiona, subverte e transborda as divisões autocráticas entre o político e o pessoal, os desejos hetero e homossexuais, o ativismo e a produção de conhecimento, poesia e prosa, derrubando as categorias disciplinadas do 
conhecimento. Trata-se de uma obra queer, por excelência, em estilo e conteúdo.

A coletânea é resultado da Conferência Anarquismo e Sexualidade, realizada na Universidade de Leeds, em 2006, cujo objetivo foi discutir anarquia sexual sem preconceitos políticos e culturais.

Qual a importância do anarquismo para entender a sexualidade? $O$ que significa 0 anarquismo sexual além de desordem ou amoralidade?

Os autores entendem o anarquismo sexual não como ideologia, mas como "ética das relações de poder", que, colocadas em prática, seriam completamente diferentes daquelas promovidas pelo Estado, pelo capitalismo, pela supremacia branca e pelo sexismo.

Promovem um anarquismo compromissado com a diversidade, uma ética que contrasta com a sociedade massificada, o Estado regulador e a racionalidade burocrática, mas respeita e defende a diversidade cultural e ecológica.

Anarquia sexual aparece como sinônimo da decadência ocidental, contra ela emerge o fundamentalismo político e/ou religioso, defendendo a 'ordem sexual natural' e a hierarquia de gênero como trincheiras contra essa ameaça à civilização, que ataca as fundações da sociedade, a forma de terrorismo, o caos.

Porém, o maior perigo reside no fato de o anarquismo e o inconformismo sexual terem poder de corroer as estruturas sobre as quais se assentam as relações de poder. Despertam desejos perigosos que provocam a resistência daqueles cujo poder depende da manutenção do status quo.

Se as relações de dominação sustentamse na diferenciação dos papéis de gênero e na organização da sexualidade, anarquizá-las corrói a estrutura social, forja novas atitudes corporais, conecta o social à literatura e à arte, apoia políticas feministas e a liberação gay.

Trazer o anarquismo sexual dos porões do ativismo político para as salas da academia, integrar conhecimento ao compromisso politico, desafiar o status quo educacional e contribuir para novas abordagens e visões de mundo foi processo doloroso que enfrentou a estigmatização da falta de seriedade acadêmica por lidar com temas pouco 'nobres'. O preconceito institucional e o desprezo dos pares, frequentemente, recaem sobre os que realizam estudos anarquistas, gays e lésbicos. A resposta foi uma avalanche de produção e publicações desses estudos, abrindo possibilidades e oportunidades para que outros novos atravessassem $\circ$ umbral do 'templo do saber'. Essa é outra razão para encarar o livro como desafio e resistência.

Estudiosos da teoria queer e da anarcossexualidade atingem audiências variadas, constroem pontes para transpor gaps entre teoria e ativismo, colocam nos salões nobres os becos escuros, 'onde um vago Ravachol mistura enxofre e limalha de ferro numa velha marmita', deixando a sociedade rica, armada e santificada em pânico. A linguagem acadêmica sob nova roupagem e a garantia ao acesso das ideias são a matéria constitutiva das pontes, sem medo ou pudor de publicar em panfletos ativistas, mesmo rechaçados por carecer de status acadêmico, desqualificados. O que se pretende é forjar uma metodologia anarquista, renunciando os controles, desafiando limites e hierarquias e promovendo espaço para novas ideias emergirem.

Inspirados na ascensão de movimentos globalizados e ondas do anarquismo ativista/ acadêmico, colocam a ética anarquista em prática, direcionam o foco para a equidade de raça, classe e gênero, liberdade e violência e o fim da sociedade do controle.

Duas transformações recentes na geopolítica mundial do século XX reacenderam o interesse pelo conjunto teórico e por recursos práticos do anarquismo para mudar o rumo da sociedade: o pensamento pós-estruturalista e a ascensão de movimentos globais anticapitalistas.

Foucault, Deleuze, Guattari, inspirados nos movimentos de Maio de 1968, contribuíram criticamente com as tradições anarquistas. Os franceses complementam, sem substituí-las, sofisticam a natureza do poder e das subjetividades e terminam por ecoar nos pensamentos feministas, pós-colonialistas e teorias queer.

Em segundo lugar, a longa história de ação direta inspira zapatistas, táticas queer, protestos em massa contra a Organização Mundial do Comércio em Seattle, 1999, sem comando definido, embora sob influência de ativistas conhecidos, como John Zerzan, que promovem manifestações globais explosivas.

$\mathrm{Se} O$ anarquismo tradicional desafiou nacionalismos e hierarquias de classe, a teoria queer, nos anos 1990, criticou a identidade sexual, estável e centrada nas fronteiras do corpo e da sexualidade, reavaliou discursos fixos e interrogou sobre diferenças naturais e hierarquias sexuais.

Os ensaios deste livro tratam da ética da liberdade, da resistência e do poder cotidiano, realizados de várias maneiras, através de múltiplos instrumentos. Como ética cotidiana, busca escutar mais que falar, não fala pelo outro nem o representa; ética do cuidado, em vez do 
controle. Amor e solidariedade articulados à sexualidade anárquica são a resposta a uma sociedade desconectada, atomizada e autoritária. Escutamos nossos corpos, desejos, os outros humanos e não humanos, imaginamos nossas vidas, vivenciando nossa sexualidade.

Como podem sexualidade, paixão e desejo ajudar a repensar os rumos da sociedade em temas menos vibrantes como economia, ecologia e poder? Como se coloca em prática o anarquismo sexual? Como se transforma a liberdade política em algo queer? É esse o desafio dos autores que compõem a coletânea.

Jane Alexander, em "Alexander Berkman: Sexual Dissidence in the First Wave Anarchist Movement and its Subsequent Narratives", retoma o passado do anarquismo, reacessa os escritos de Berkman na prisão e desenterra sua experiência num contexto temporal. Berkman vê o injusto preconceito da sociedade contra o amor entre homens e descreve a diluição do seu próprio preconceito, na experiência da prisão, com o companheiro de cela - 'kiddie' , revelando como o amor surge nos ambientes mais inóspitos.

Stevphen Shukaitis, em "Nobody knows What an Insurgent Body can do: Questions for Affective Resistance", ressignifica a intimidade no interior das solidariedades do feminismo e das lutas queer. Discute a remuneração do trabalho doméstico e a efetividade de lutas que se dão às custas do afeto, da comunalidade e da afeição entre participantes nos movimentos sociais. Não interessa saber se a luta é efetiva, eficiente, organizada, mas se é afetiva, se resiste às relações de poder e constrói novas relações entre os resistentes. Afetividade, como o elemento essencial nas lutas de resistência, promoveria maior efetividade aos esforços para reconfigurar as relações sociais.

Toma o exemplo da organização espanhola Precarias a la Deriva, na qual o peso da afetividade consolidou novas formas de luta, o biossindicalismo, para considerar a necessidade de cada trabalhador, segundo seu gênero e posicionamento sexual.

Lena Eckert, em "Post(-)Anarchism and the Contrasexual Practices of Cyborgs in Dildotopia", demonstra como o poder entrincheira-se nos microcosmos cotidianos. Pensa o simbolismo lacaniano do falo, Foucault e as tecnologias do self contextualizadas na crítica fundacional pósanarquista: se o poder simbólico se difunde por todos os lugares, há a exigência de uma resistência igualmente dispersa por todos os lugares.
Eckert questiona a função simbólica do falo, na esteira de Preciado, e o debate sobre a contrassexualidade com a subversão do dildo, implodindo a diferença sexo/gênero baseada num órgão sexual. Ao destronar o falo, o dildo representa uma sexualidade sem diferença sexual, já que a arquitetura corporal é política, preconiza a erotização do corpo inteiro, reconfigurando as hierarquias do prazer após a descentralização do falo. Apropria-se de Butler, do discurso da performatividade normativa $e$ do falo lésbico; e de Haraway, com a imagem do cyborg na dildopia pós-humana, como cidadão contrassexual.

Em "On Anarchism: An Interview with Judith Butler", Heckert explora questões de gênero, sexualidade e poder. Ela contrasta o movimento gay ocidental com outras formas de anarquismo queer. Vê o primeiro sendo recrutado e afiliado ao Estado, buscando assegurar posições de privilégio e ignorando a violência do Estado racializado; e o último tentando desmantelar as hierarquias. Ela faz um jogo binário, mas resiste à tentação de esboçar uma divisão entre fora e dentro do Estado, contra ou a favor da lei. Em vez disso, aponta fragilidades nos códigos legais e nos regimes, proporcionando espaços para a possível subversão em favor da soberania popular. Butler conecta Benjamim e Althusser com os Anarchists Against the Wall, os zapatistas, as questões cotidianas de dignidade e sobrevivência, revela a possível e valiosa fronteira entre o ativismo político e a academia com formato queer. Essa grande contribuição estimula 0 engajamento entre a teoria feminista e o pósanarquismo.

Laurence Davis, em "Love and Revolution in Ursula Le Guin's Four Ways to Forgiveness", nos leva, pelas suas mãos, a imaginar a vida como escudo protetor contra restrições autoritárias para impedir que outras pessoas deem forma à nossa existência. ${ }^{3}$ Davis coloca amor e revolução entrelaçados em "Four Days to Forgiveness (1995)". Aqui, o anarquismo nada vale se não implicar a revolução da vida cotidiana. $\mathrm{Na}$ contramão dos movimentos marxistas, a revolução anarquista revolve modos de vida e relações de amor e sexo. "Four Days" traz quatro histórias de traição, perdão, política, revolução social e amor. Amor e sexualidade não são suplementos ou pano de fundo para ação política, mas elementos fundamentais para sua realização. Em Le Guin, ciúmes e traição prendem-se a noções e expectativas de gênero rígidas, transformadas através de reciprocidade e expressão revolucionária. O poder se dissolve, 
se anula na "prática revolucionária paciente, construtiva, orgânica e aberta, em última análise, enraizada na transformação do espírito individual (p. 114).

Lewis Call também se debruça sobre a ficção em "Structures of Desire Postanarchist Kink in the Speculative Fiction of Octavia Butler and Samuel Delaney". Os autores afro-americanos discorrem sobre tópicos desconfortáveis, mas inspiradores de formas de vida alternativas. Embora não tenham associação com o anarquismo, em vez de dissolver as formas de poder, brincam com elas, através da bondage e disciplina, e do sadomasoquismo, formas consensuais de desejo e erotismo fortemente contrastadas com práticas não consentidas, não eróticas e não éticas, práticas de poder indesejadas que caracterizam a escravidão e que, até hoje, atingem os afrodescendentes. Call vê nos jogos de poder uma estratégia para curar as feridas psíquicas da escravidão.

Jamie Heckert, em "Fantasies of an Anarchist Sex Educator", aborda temporalidade, corporeidade, ética e emoção na educação sexual e sexualidade juvenil, um campo atraente para a teoria feminista e o pós-anarquismo. Discorre sobre o poder das histórias, através das histórias sexuais, como os indivíduos percebem relatos de violência doméstica ou como é a experiência de crescer como diferente no mundo monocromático sexualmente. Ouvir a si e aos outros abre caminho para a realização erótica e o desejo anárquico. Intensivamente pessoal e profundamente político, contar histórias é fonte de conhecimento queer, cuja centralidade está na conexão e no amor. Isso não pode ser adiado para depois de nenhuma revolução.

Kolarova, em "Sexuality Issues in the Czesch Anarchist Movement", resgata a tradição do início do século $\mathrm{XX}$, interrompida pelo comunismo, e apresenta $o$ anarquismo tcheco que reemergiu nos anos 1980. A autora analisa como a sexualidade insere-se no anarquismo tcheco que antes privilegiava os aspectos econômicos e as organizações industriais, como incorpora questões do feminismo e direitos gays. O custo dessa inserção foi tornar as anarcofeministas e o movimento queer alvo de violência dos fascistas, durante as Paradas Gays, em represália à cooperação entre ambos.
Galvin Brown, em "Amateurism and Anarchism in the Creation of Autonomous Queer Spaces", oferece estudos de casos da geografia autônoma queer. O questionamento da autoridade não se limita ao plano políico, inclui formas de expertise como os exemplos demonstram. Essas formas de expertise operam como escolas de anarquismo, sem Bakunin ou ativismo, mas num acampamento pagão ou boates queers, Brown viaja por experimentos de relações sociais autônomas. Assim procedendo, coloca-nos frente a um futuro queer possível, outro mundo além-Estado, além-capitalismo, alémsocialismo.

É preciso ter em mente que hierarquias não são espaços de controle perfeito, as brechas autônomas fissuram e rompem a solidez da estrutura hierárquica. Rompemos hierarquias quando percebemos e nos relacionamos, com o outro, como iguais.

Brown ressalta a importância do ritual na tessitura da comunidade, os queer pagãos partilham o ritual como experiência de estar junto, trocar a dor e a delícia de estar vivo.

Concluindo, Kristina Weaver, em "Afterwords: On the Phenomenology of Fishbowls", compartilha o experimento da estrutura do desejo utilizada durante a Conferência em Leeds, com a criação de um espaço queer autônomo. Sua narrativa convida a organizarmos eventos com novos formatos, como campos para novas possibilidades.

\section{Notas}

1 Jamie Heckert é um estudioso independente, como muitos teóricos do anarquismo. Fundador da Anarchist Studies Network, escreve sobre ética, erotismo e ecologia em periódicos acadêmicos e ativistas.

${ }^{2}$ Richard Cleminson é professor e pesquisador do Centro Interdisciplinar de Estudos de Gênero da Universidade de Leeds e editor associado da revista inglesa Anarchist Studies.

${ }^{3}$ Ursula LE GUIN, 2004, p. 208.

\section{Referências}

LE GUIN, Ursula K. "The Operating Instructions." In: The Wave in the Mind: Talks and $\overline{\text { Essays }}$ on the Writer, the Reader, and the Imagination. Boston, MA: Shambala, 2004. p. 206-210.

Loreley Gomes Garcia Universidade Federal da Paraíba 